\title{
Article \\ Effect of a Recliner Chair with Rocking Motions on Sleep Efficiency
}

\author{
Suwhan Baek ${ }^{1,+} \mathbb{D}$, Hyunsoo Yu ${ }^{1,+}{ }^{\mathbb{D}}$, Jongryun Roh ${ }^{2}$, Jungnyun Lee ${ }^{2} \mathbb{D}$, Illsoo Sohn ${ }^{3}$, Sayup Kim ${ }^{2, *}$ \\ and Cheolsoo Park $1, *$ (D)
}

1 Department of Computer engineering, Kwangwoon University, Seoul 01897, Korea; zhsjzhsj@gmail.com (S.B.); byeng3@kw.ac.kr (H.Y.)

2 Digital Transformation RnD Department, Korea Institute of Industrial Technology, Ansan 15588, Korea; ssaccn@kitech.re.kr (J.R.); blueleen2@kitech.re.kr (J.L.)

3 Department of Computer Science and Engineering, Seoul National University of Science and Technology, Seoul 01811, Korea; isohn@seoultech.ac.kr

* Correspondence: sayub@kitech.re.kr (S.K.); parkcheolsoo@kw.ac.kr (C.P.)

$+\quad$ These authors contributed equally to this work.

check for

updates

Citation: Suwhan, B.; Hyunsoo, Y.; Jongryun, R.; Jungnyun, L. ; Illsoo, S.; Cheolsoo, P. Effect of a Recliner Chair with Rocking Motions on Sleep Efficiency. Sensors 2021, 21, 8214. https://doi.org/10.3390/s21248214

Academic Editor: YangQuan Chen; Subhas Mukhopadhyay; Nunzio Cennamo; M. Jamal Deen; Junseop Lee; Simone Morais

Received: 14 October 2021 Accepted: 30 November 2021 Published: 8 December 2021

Publisher's Note: MDPI stays neutral with regard to jurisdictional claims in published maps and institutional affiliations.

Copyright: (c) 2021 by the authors. Licensee MDPI, Basel, Switzerland. This article is an open access article distributed under the terms and conditions of the Creative Commons Attribution (CC BY) license (https:/ / creativecommons.org/licenses/by/ $4.0 /)$.

\begin{abstract}
In this study, we analyze the effect of a recliner chair with rocking motions on sleep quality of naps using automated sleep scoring and spindle detection models. The quality of sleep corresponding to the two rocking motions was measured quantitatively and qualitatively. For the quantitative evaluation, we conducted a sleep parameter analysis based on the results of the estimated sleep stages obtained on the brainwave and spindle estimation, and a sleep survey assessment from the participants was analyzed for the qualitative evaluation. The analysis showed that sleep in the recliner chair with rocking motions positively increased the duration of the spindles and deep sleep stage, resulting in improved sleep quality.
\end{abstract}

Keywords: rocking motion; sleep quality; sleep staging; spindle; real world data; deep neural networks

\section{Introduction}

Sleep plays a major role in maintaining an individual's physical health, owing to its involvement in several physiological processes such as tissue healing and repair [1-3]. Moreover, several studies claimed that sleep could critically affect physical and cognitive performances, thereby encouraging researchers to investigate how to achieve effective rest and improved sleep quality in a limited amount of time. Improved sleep quality could result in having a healthier condition and better quality of life [4-6]. Specifically, good sleep quality would relieve the risk of acquiring insomnia [7-10], which could critically impair the immune function [11] and cause neurodegenerative disorders and cardiac diseases [12]. On the other hand, poor sleep quality is associated to coronary artery diseases in adults such as myocardial infarction [13-16] and affective states like depression and anxiety $[17,18]$, which may affect an individual's work productivity, social functioning, and safety. These results suggest that the sleep quality is as crucial as sleep quantity in ensuring life satisfaction [19], which is one of the core indicators of a healthy lifestyle.

The benefits of sleep on angle-adjustable recliner chairs have been reported several times. It has been reported that sleep in an angle-adjustable chair, such as a recliner, improved the sleep quality through the sleep at a higher angle of posture or the neck [20-22]. In particular, it has been proven that some sleep disorders could be medically improved in patients with sleep apnea [22-25] and nocturnal gastroesophageal reflux through sleep in a recliner [26]. In this paper, we propose an additional way to further improve the quality of sleep with providing a rocking motion to the recliner. This study introduces a new swinging mechanism with rocking motions, which improves the quality of a day-time sleep in a recliner. Therefore, a new swinging recliner chair is proposed to improve the nap environment with controlling the rocking and reclining functions. 
In order to analyze the quality of sleep in the proposed recliner chair, we estimate five different sleep stages, Wake, NREM1 (N1), NREM2 (N2), NREM3 (N3), REM, using every $30 \mathrm{~s}$ epoch of the brain waves signal based on American Association of Sleep Medicine [27]. With this, various sleep parameters [28], including total sleep time (TST), total N1 sleep (TN1), total N2 sleep (TN2), total N3 sleep (TN3), total REM sleep (TR), sleep efficiency (SE), slow-wave sleep ratio (SWS\%), and SWS to light sleep ratio (SL\%), and quantitative comparisons of the overall sleep stages are investigated for the qualitative and quantitative measures of sleep quality based on the functions of the swinging chair. Additionally, we also investigate the spindle components in the recorded brain waves during the nap, which is a specific brain wave pattern occurs during sleep because of bursts of neural oscillatory activity by interplay of the thalamic reticular nucleus (TRN) and other thalamic nuclei [29-31]. Since it has been reported that spindle plays a major role in the benefits of memory enhancement and sensory shut down for reducing wake up [32-35], spindle element could be one of major elements to evaluate quality of sleep [29,36]. This study analyzes the quantitative growth of the overall spindles based on two types of spindles, namely the slow and fast spindles $[37,38]$. There are several conflicting reports regarding these two types of spindles in terms of their roles in various cognitive tasks. Since there seems to be only a consensus on the quantitative effects of spindles to sleep quality and not on their mechanisms and qualitative effects, this study only conducted the quantitative analysis on the patterns of the slow and fast spindles. A deep learning model is designed to estimate the sleep phases, which decide the multiple sleep parameters, and the frequency analysis is utilized to detect the spindle components.

The plan of the paper is as follows. First, we propose a novel experimental method that produces rocking motions in a recliner chair. Here, the characteristics and factors of the 'swinging-chair' and the descriptions of the participant and the experimental environment are provided. Then, we discuss the automatic sleep staging methods for the sleep quality evaluation, where the architecture of the deep neural networks used to classify the sleep stages is addressed.

\section{Materials and Methods}

\subsection{Recliner Chair}

A recliner chair, which reliably reproduces identical movements, was designed using a $200 \mathrm{~W}$ linear actuator motor that provides robust, steady, and repetitive swinging motions to analyze the nap quality in the swinging chair. A link fixation mechanism yields a specific trajectory with a $\pm 5 \mathrm{~cm}$ margin of error depending on the experimental condition. The range of the swinging motion was fixed at $10 \mathrm{~cm}$ head-on for all conditions [39], and the acceleration during the swing was $0.3 \mathrm{~m} / \mathrm{s}^{2}$ based on the ISO reference [40]. The swing cycle of the recliner chair is once per $4 \mathrm{~s}$, that is $0.25 \mathrm{~Hz}$. These operations were controlled by a microprocessor and managed by continuous logging of the accelerator signals. In addition, it automatically calibrates each swinging cycle using the position sensitive device (PSD) sensor to continuously track and minimize the trajectory error and calibrate the error values caused by the swinging environment or motion artifacts of the participants. For the comfort of the user, the back of the chair was fixed to $14^{\circ}\left( \pm 2^{\circ}\right)$ and the seat of the chair to $36^{\circ}\left( \pm 2^{\circ}\right)[41]$, as shown in Figure 1 . There are two types of rocking conditions, namely 'Condition $\mathrm{A}^{\prime}$ and 'Condition $\mathrm{H}$.' The chair creates a lateral pitch motion on the $y$-axis in Condition A, while the chair provides a back-and-forth rectilinear motion on the $x$-axis in Condition H. Moreover, 'Condition B' is considered as the control in this study, in which the chair does not move in any axis. Figure 2 shows the illustrations of the chair movements in all conditions. 

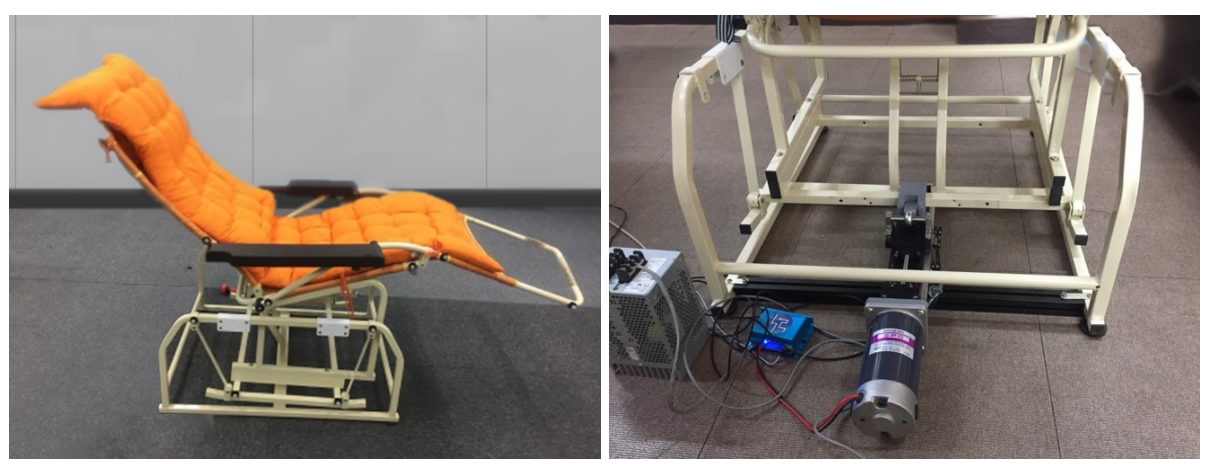

Figure 1. Designed recliner chair.
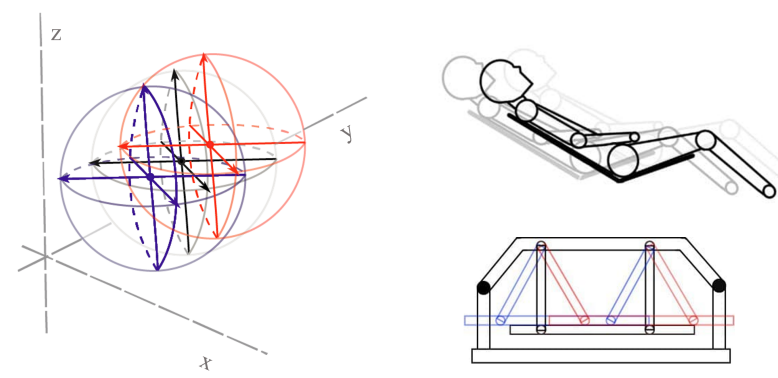

(a) Condition A
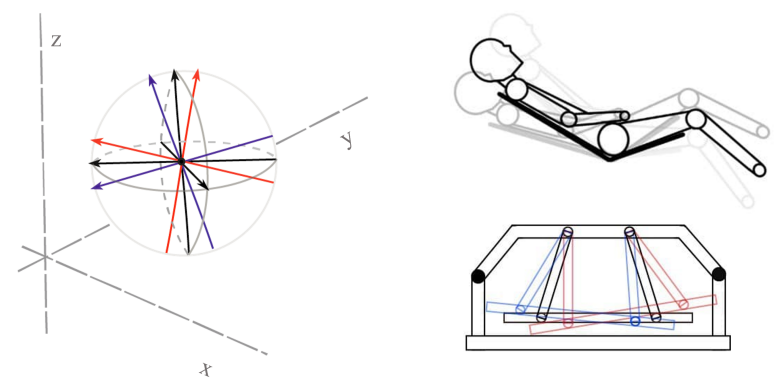

(b) Condition $\mathrm{H}$
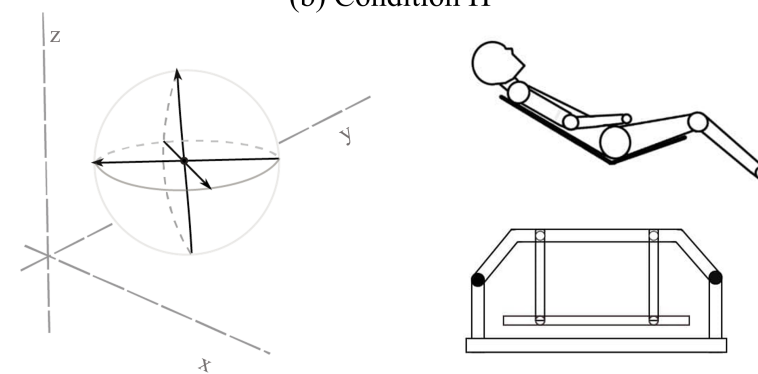

(c) Condition B

Figure 2. Rocking motion of the designed recliner chair. (a) Trajectory in the recliner Condition A. It has $y$-axis pitch movements; (b) Trajectory in the recliner Condition $\mathrm{H}$. It has $y$-axis back-and-forth movements; (c) The control group is Condition B. It has no movement during the experiment.

\subsection{Experimental Protocols}

Fifteen participants (age mean $=25.375, \mathrm{SD} \pm 2.99$ years old, all male) with no history of sleep disorders were recruited for the nap experiment. All participants napped on the recliner chair three times for three hours in all three conditions. They were asked to follow a strict sleep and diet regimen the day before the experiment. The average body mass index (BMI) of the participants is $23.01 \pm 2.09$, and the average Pittsburgh sleep quality index (PSQI) [42] is $5.625 \pm 3.22$. Moreover, we controlled the environmental elements such as sound intensity, room temperature, relative humidity, and luminosity to ensure that 
the sleep environment was controlled. Moreover, during the experiment, the luminosity was controlled to be lower than 10 lux [43] and the noise level of the room was $30 \mathrm{~dB}$ on average and lesser than $45 \mathrm{~dB}[44,45]$. The room temperature was fixed at $23^{\circ} \mathrm{C}$ [46], while the relative humidity was set at $45 \%$ [46] using an air conditioner. Furthermore, sleep scoring two-channel electroencephalography (EEG) signals [47-49] were recorded from the participants during their entire nap periods.

Two scalp electrodes on Fp1 and Fp2 shown in Figure 3 were attached as working electrodes referenced to the left earlobe (A2) and grounded to the right earlobe (A1) to obtain the EEG signals from the participants. In addition, the physical removal of the very top layer of the skin (i.e., stratum corneum) and other foreign substances on the epidermis was carried out before the attachment of the electrodes and their maximum impedance was limited under $5 \mathrm{k} \Omega$. A bandpass filter [50] in the range between 0.5 and $55 \mathrm{~Hz}[51,52]$ was applied to the recorded EEG signals to eliminate unnecessarily ambient noise such as motion artifacts from the recliner chair, and a notch filter was used to remove $60 \mathrm{~Hz}$ power line noise [53]. Moreover, MP36 (BIOPAC Systems Inc, Goleta, CA, USA) and gUSBamp (Gtec, Albany, New York, USA) were utilized to record EEG signals at 500 and $600 \mathrm{~Hz}$ sampling rates, respectively. The amplifiers were operated at a sufficient distance from the chair to prevent any interference of electromagnetic noise generated from the actuator of the recliner chair. Each participant conducted the nap experiments of three conditions in randomized order. In addition, all participants had been instructed to nap under similar conditions as the experiment before the actual recording to avoid the first night effect [54]. The nap time was limited from 14:00 to 17:00 considering the circadian rhythm of the participants, and they were under strict sleep and dietary restrictions as previously mentioned. All participants were prohibited from consuming caffeine and other psychiatric drugs and were also provided diet and sleep schedules, as shown in Figure 4.

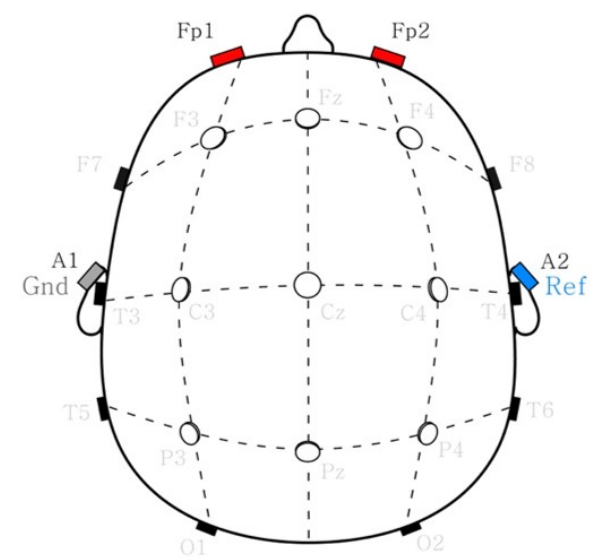

Figure 3. EEG montage of 10-20 systems [55], where Fp1 and Fp2 were used working electrodes referenced to $\mathrm{A} 2$ and grounded to $\mathrm{A} 1$.

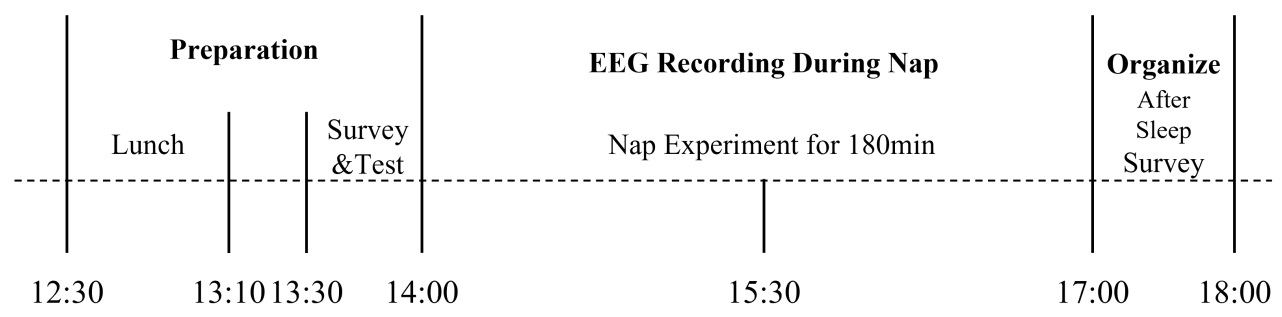

Figure 4. Experimental procedure to record EEG signals during the nap on the recliner chair for measuring nap time EEG. 
Moreover, the participants were subjected in a more controlled condition two hours before the experiment, that is, being banned from drinking caffeinated drinks [53] and performing rigorous activities [56] while being watched by the researchers to avoid any bias. In addition, a PSQI [42] survey was conducted before the experiment for a qualitative analysis of the sleep quality of the participants, including the amount, depth, and comfort of sleep over a month, providing a subjective assessment to determine the sleep disorders of the participants. The PSQI varies from 0 points to a maximum of 21, which is segmented into 7 levels according to the scoring method. A high PSQI score indicates poor quality of sleep, and a score of 5 or higher decides a poor sleeper, while less than 5 tells a good sleeper [42,57]. In this paper, based on the PSQI score, the subjects are divided into 'good sleeper' groups and 'bad sleeper' groups, and then it is investigated which group achieves significant sleep quality improvement on the proposed recliner. Moreover, the participants and their environments were continuously monitored using a web camera to observe any instability during the experiment. After the experiment, a subjective sleep quality survey [58] was conducted again for another qualitative analysis, including the time of sleep and numbers of waking time.

This experiment was approved by the Institutional Review Board of Kwangwoon University (IRB No. 7001546-20200728-HR(SB)-006-01).

\subsection{Sleep Stage Estimation}

The sleep quality could be estimated using various sleep parameters based on the sleep scoring results. In this study, the sleep stages were defined using an automatic machine learning algorithm with a significantly acceptable performance than that of a manual polysomnography (PSG) scoring that is commonly used by clinicians [59-61]. The neural network-based sleep scoring algorithm, DeepSleepNet [62], trained using the Wisconsin Sleep Cohort dataset [63,64], was applied to test the participants' EEG signals. In this paper, since the quality of sleep is analyzed through the AASM [27] based five-stage sleep states, the proposed model classifies the possible Wake, NREM1, NREM2, NREM3, and REM sleep stages using the input EEG signals.

The model consists of two small and large convolution neural networks (CNN) [65-68], as shown in Figure 5, which are divided into two branches and then merged through a concatenation, where a small CNN architecture captures temporal properties and a large $\mathrm{CNN}$ architecture extracts frequency information for the sleep stage estimation [62]. The bidimensional long-short term memory (LSTM) $[65,69,70]$ is utilized in the DeepSleepNet to exploit the information of both hidden states at time inferences ' $t-1$ ' and ' $t+1$ ' in the sequence.

As reported by Supratak, A. et al. [62], a two-step training process is required to estimate the sleep stages using the deep learning model, that is, a pre-training and a finetuning process. Before the pre-training procedure, oversampling and undersampling were conducted to solve the class-imbalance problem. The pre-training process does not train the entire model in Figure 5, but only trains the upper two convolution network layers. In this study, EEG signals of 129 participants from a Fp1 configuration recorded at $100 \mathrm{~Hz}$ from the Wisconsin Sleep Cohort dataset were used to train the model. The training was performed with 48,860 epochs for each stage, extracted through the undersampling based on the number of the N1 sleep stage, which has the smallest number of epochs among the five stages. When training two convolution network layers, an ADAM optimizer [71] with a batch size of 100 and a learning rate of $10^{-3}$ were used.

In the fine-tuning process, randomly shuffled sequential data was utilized rather than the class-balanced dataset and the entire model depicted in Figure 5 was trained with applying two pre-trained CNN parameters to the CNN model. The optimizer used in this step is the ADAM optimizer, and the batch size is set to 10. In order to train the sequence residual learning part including the LSTM, its learning rate was set to $10^{-3}$, while the learning rate was set to $10^{-4}$ since the pre-trained parameters were applied to the two convolution network layers. For regularization, two techniques were applied; one is a 
dropout of neurons with 0.5 probability to prevent overfitting as shown in Figure 5, and the other is an L2 to prevent the occurrence of too large parameters in the model. This L2 weight decay is implemented during the training process of the two convolution network layers in order to prevent the overfitting due to the ambient noise or movement artifacts. However, it was not applied in the sequence residual learning because it could limit the model capabilities of learning the long-term dependency. The values of sleep parameters were calculated to analyze the quality of sleep based on the results of the five-sleep stage estimation using the model. Furthermore, a quantitative analysis of the sleep quality was conducted using the calculated sleep parameters.

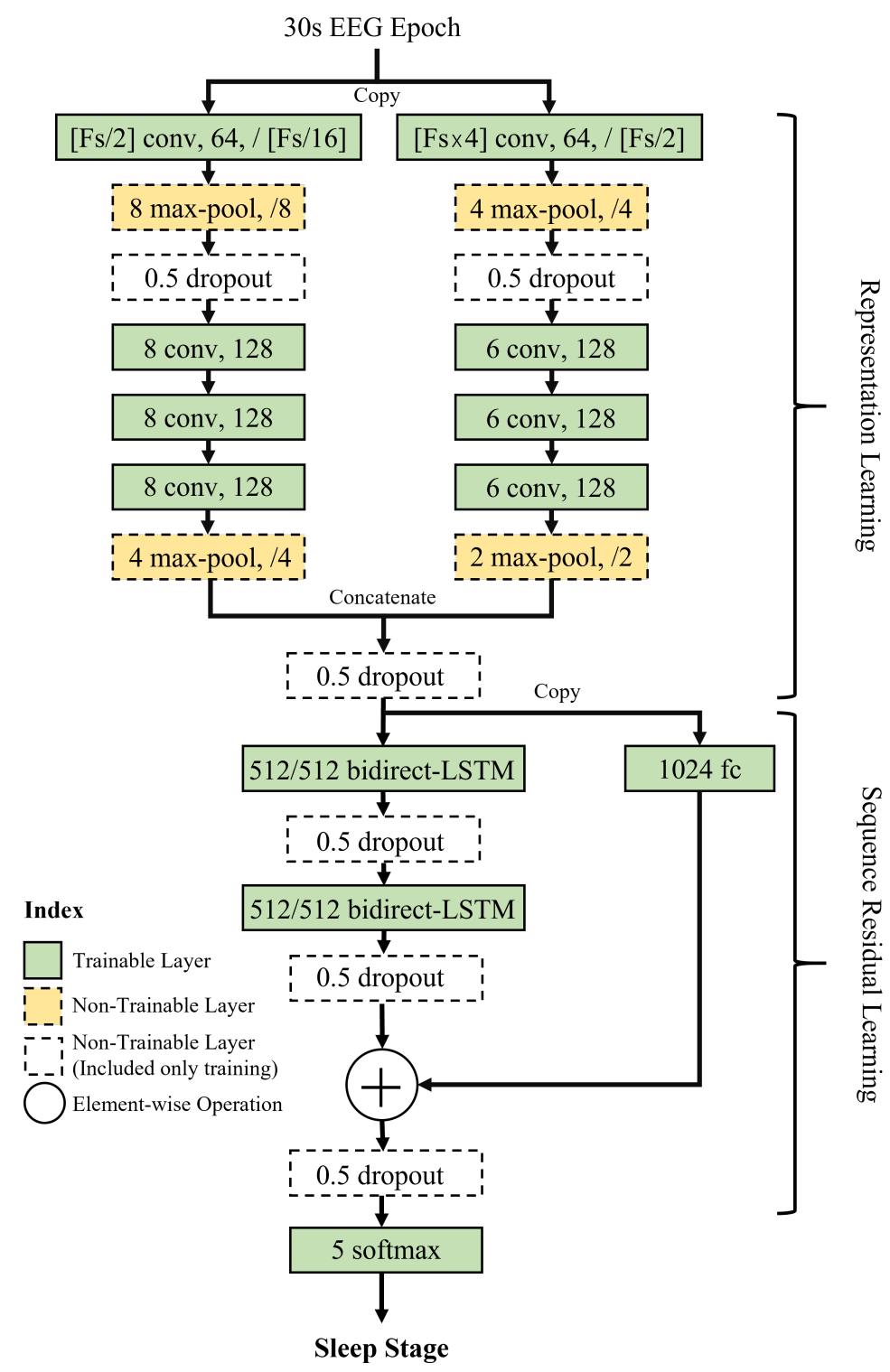

Figure 5. Architecture of the DeepSleepNet. It has two different learning parts such as the CNN and LSTM. The CNN layer proceeds the representation learning and LSTM proceeds the sequence residual learning. The EEG sampling rate $(\mathrm{Fs})$ is a specification for the first convolutional layer.This model classifies the five sleep stages, defined by AASM [27] using the 30 s EEG epochs.

\subsection{Sleep Spindle Estimation}

A sleep spindle is a unique characteristic that marks the beginning of an N2 sleep stage since it is used to define the transition from N1 to N2 stage. A sleep spindle is typically observed to have frequency components between $11-16 \mathrm{~Hz}$, which is also known as a 
sigma wave. There has been evidences that certain characteristics of the spindle activity are linked to various cognitive and motor functions while its exact effects on the body are only speculated upon [32,72]. Various previous studies have suggested that increased spindle activities were related to both implicit and explicit memory consolidation [73-77], while others reported that spindle deficits were related to various neurological diseases, including autism $[78,79]$ and Alzheimer's disease $[80,81]$.

The medical community considers the spindle identification by human experts as the gold standard in estimating the sleep spindle. However, there are several limitations with this method, including its unreliability in both intra-rater and inter-rater data [82,83] and its high cost. Therefore, there has been various attempts to create an automated sleep scorer that could reliably identify sleep stages and spindles [84-86].

Specifically, Lacourse et al. [60] proposed the A7 algorithm, which inspired the algorithm used in this study. The A7 algorithm tries to calculate the sleep spindle duration, oscillation frequency, amplitude of a spindle, and other properties.

On the other hand, the YASA algorithm $[61,87]$ is more economical than the A7 algorithm because it uses only three parameters instead of four but performs in similar manner [88]. The first parameter is the relative power of the sigma band frequency components compared to the broader band components ( 0 to $30 \mathrm{~Hz}$ ) that was extracted using the short-term Fourier transform (STFT) [89]. An increase of this parameter indicates that the power increase is dominant in the sigma band. Meanwhile, the second parameter is the correlation between the sigma band and the broad band components that was calculated using the Pearson correlation coefficient [90] and FIR filter [91]. Finally, the last parameter is the temporally changing root mean squared (RMS) value. The YASA algorithm can distinguish the sleep spindle components by monitoring the three parameters. Raphael et al. [87] reported $86.6 \% \pm 6.2$ accuracy and $78.5 \pm 9.4$ F1-score to detect the spindles, which is similar to the results of human experts $[60,61,87]$. Figure 6 shows an example of the detected spindle event using this algorithm in a $30 \mathrm{~s}$ epoch of the EEG signal.

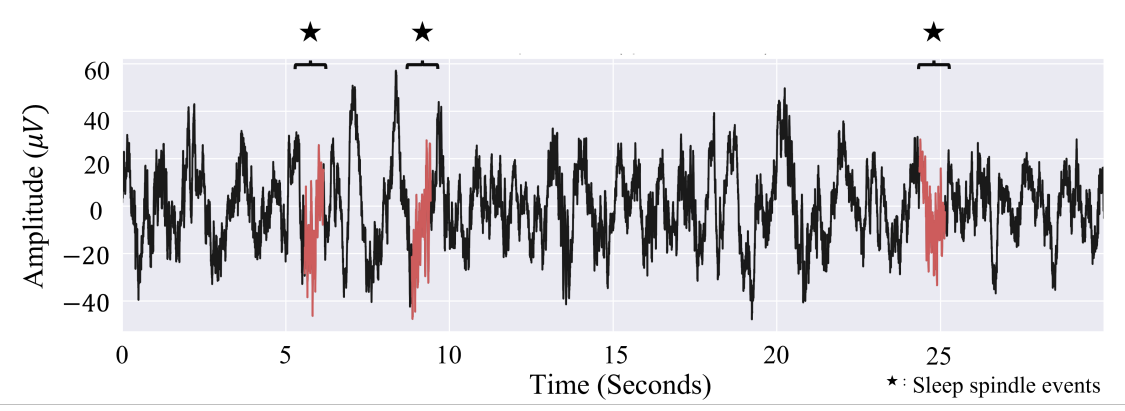

Figure 6. EEG spindle detected by YASA spindle detection algorithm. The red lines represent the detected spindle.

\subsection{Sleep Parameters}

Various sleep parameters, including TIB (time in bed), which total time in bed while experiments, TST (total sleep time) and TSP (total sleep period), are calculated for the quantitative analysis of sleep quality. Specifically, TST is the sum of the total sleep length except wake among all sleep stages, while TSP is the amount of the actual time spent in the sleep cycles estimated by the duration between the beginning of the first N1 sleep stage and the wake. Other sleep parameters, including the parameters about deep sleep periods such as N3 and about the light sleep and wake periods such as N1, N2, and REM stages, were also investigated to achieve more accurate analysis. Additionally this study uses the sum of the N1 sleep stages (TN1), the sum of the N2 sleep stages (TN2), the sum of the N3 sleep stages (TN3), the sum of REM sleep stages (TR), and N1, N2, N3 and REM ratios to TST (N1\%, N2\%, SWS \%, REM\%), to analyze the sleep quality based on the absolute amount and the relative amount of sleep stages. Along with this quantitative analysis of the sleep quality, parameters related to the latency of the sleep stages, were also analyzed, 
where the sleep latencies to the light (N1 and N2), deep (N3) and REM sleep stages are investigated. For further analysis of the sleep quality, SL\% (SWS ratio to the light sleep), SOL (Sleep on set latency) and SE (Sleep efficiency), are also calculated. SL\% shows the amount of the N3 sleep compared with the light sleep (N1 and N2), SOL indicates the latency to fall asleep. SE represents the total sleep time like TST, but is normalized by the TIB value. These parameters are derived using the formula in Figure 7.

\begin{tabular}{|c|c|}
\hline \multicolumn{2}{|l|}{ Sleep Parameter Index } \\
\hline Parameter & Formula \\
\hline TIB (Time in bed) & $=\Sigma$ (minutes from lights out to the end of recording) \\
\hline TST (Total sleep time) * & $=\Sigma($ Sleep minutes $)$ \\
\hline TSP (Total sleep period) & $=\Sigma($ Sleep minutes $)+\Sigma($ Wake minutes $)$ \\
\hline TN1 (Total N1 sleep) * & $=\Sigma(N 1$ minutes $)$ \\
\hline TN2 (Total N2 sleep) * & $=\Sigma(N 2$ minutes $)$ \\
\hline TN3 (Total N3 sleep) * & $=\Sigma(N 3$ minutes $)$ \\
\hline TR (Total REM minutes) * & $=\Sigma($ REM minutes $)$ \\
\hline $\mathrm{N} 1 \%(\mathrm{~N} 1$ percentage $) *$ & $=\Sigma(N 1$ minutes $) / T S T$ \\
\hline $\mathrm{N} 2 \%$ (N2 percentage) $*$ & $=\Sigma(N 2$ minutes $) / T S T$ \\
\hline SWS\% (SWS percentage) * & $=\Sigma($ N3 minutes $) / T S T$ \\
\hline REM\% (REM percentage) * & $=\Sigma($ REM minutes $) / T S T$ \\
\hline SL\% (SWS to light sleep ratio) & $=\Sigma(N 3$ minutes $) /[\Sigma(N 1$ minutes $)+\Sigma(N 2$ minutes $)]$ \\
\hline SE (Sleep efficiency) * & $=T S T / \Sigma($ minutes in bed $)$ \\
\hline SOL (Sleep on set latency)* & $=\Sigma($ recording minutes $)-T S T$ \\
\hline
\end{tabular}

N1 : NREM stage 1; N2 : NREM stage 2
N3 : NREM stage 3; SWS : Slow-wave sleep

Sleep parameters that higher value
indicates better sleep quality
- SE $\quad$ - SL\%
- REM\% $\quad$ SWS\%
- TR
Sleep parameters that higher value
indicates low sleep quality
- N1\%
- N2\%
- SOL
Specified optimal value for healthy subject
- TN1 $\quad$ - TIB
- TN2 - TST
- TN3
* Recommended to be a reported parameter for
polysomnography by the AASM Manual for the
Scoring of Sleep and Associated Event, version
2.4., $2017 . \quad$

Figure 7. Sleep parameter index and its simplified formula.

\subsection{Self-Reported Sleep Quality Analysis}

The self-reported sleep quality was investigated as a subjective and qualitative evaluation of the nap. All participants answered the questionnaire proposed by ÅKerstedt et al. [58] regarding the evaluation of their own sleep after naps, resulting in comprehensive results on the sleep quality by comparing the self-reported feedback with the EEG measurement. In this study, the qualitative sleep quality of the participants based on the self-reported evaluation time, awake time, and sleep latency parameters.

\section{Results}

\subsection{Sleep Stage Automation Evaluation}

The model used in the experiment needs to be re-evaluated using the EEG from Fp1-M1 and Fp2-M1 configurations since the simulations in the DeepSleepNet study [62] have been conducted on the EEG signals from Fpz-Pz and Cz-Oz channel configurations. In addition, the Wisconsin Sleep Cohort dataset $[63,64]$ recorded with the Fp1-M1 and Fp2-M1 channel configurations was employed to train the DeepSleepNet model with the recliner channel configurations. The performance of DeepSleepNet trained using the Wisconsin Sleep Cohort dataset is shown in Table 1. Results show that the average accuracy of the 240 participants was $81.16 \%$, which is a similar level of the accuracy estimated by medical experts [59]. However, N1 stage is poorly detected compared with the other 
stages that have been consistently addressed in the previous reports [62], and the N1 and N2 sleep stages are usually considered as one stage, 'Light sleep' [27] in four-sleep stage taxonomy [92-97]. We also applied the four stage scheme with combining the N1 and N2 stage as one 'Light sleep' to analyze the sleep quality in multiple approaches.

Table 1. Evaluation of DeepSleepNet using the Wisconsin Sleep Cohort dataset.

\begin{tabular}{lccccc}
\hline & Wake (\%) & N1 (\%) & N2 (\%) & N3 (\%) & REM (\%) \\
\hline Accuracy & $94.87( \pm 4.93)$ & $92.24( \pm 4.43)$ & $88.20( \pm 5.59)$ & $95.31( \pm 3.30)$ & $93.42( \pm 3.43)$ \\
\hline Precision & $85.00( \pm 12.37)$ & $46.25( \pm 14.98)$ & $80.64( \pm 13.96)$ & $93.00( \pm 6.34)$ & $85.10( \pm 16.50)$ \\
\hline Recall & $89.15( \pm 14.08)$ & $48.20( \pm 18.08)$ & $89.70( \pm 5.86)$ & $76.35( \pm 14.51)$ & $81.70( \pm 12.58)$ \\
\hline F1 score & $85.60( \pm 10.54)$ & $44.00( \pm 12.90)$ & $84.45( \pm 9.43)$ & $83.05( \pm 9.44)$ & $81.40( \pm 12.26)$ \\
\hline
\end{tabular}

The trained deep neural network model predicts the sleep stages of the participants sleeping in the recliner with the designed rocking motions to evaluate their sleep qualities. Figure 8 displays the estimated sleep stages of one of the participants for a $3 \mathrm{~h}$ sleep. Each sleep stage is decided in every $30 \mathrm{~s}$ epoch. 


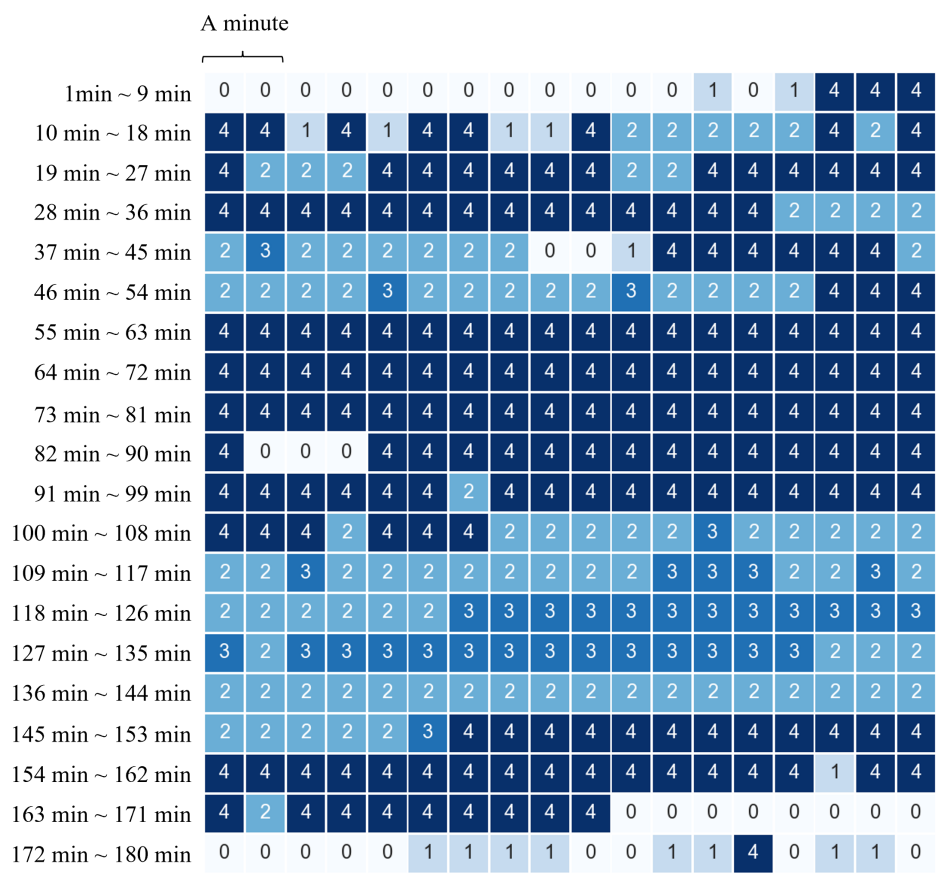

(a) Estimated sleep stage in each 30sec time epoch for a whole periods nap.

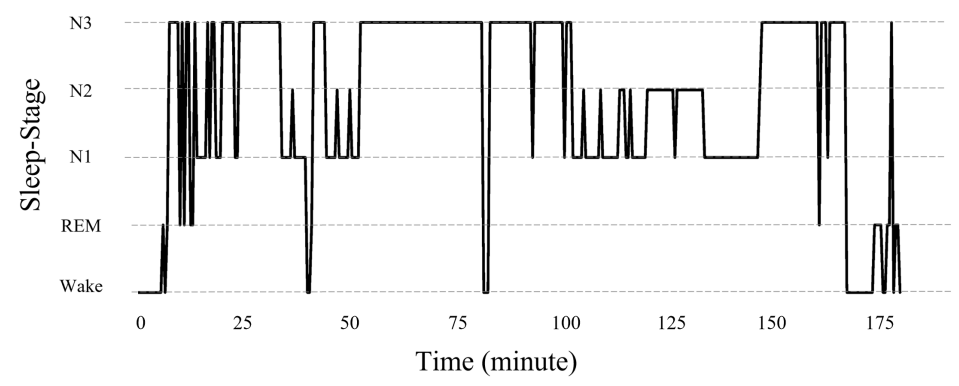

(b) Estimated sleep hypnogram during a nap

Figure 8. Estimaed hypnogram of one of the participants based on the sleep staging model. The estimation model architected by DeepSleepNet and trained by Wisconsin Sleep Cohort dataset. In (a), 0 is Wake, 1 is REM, 2 is N1, 3 is N2 and 4 is N3 sleep stage, respectively.

\subsection{Sleep Parameter Analysis}

The estimated sleep stage lengths of all 15 participants corresponding to the different recliner conditions, as shown in Figure 9 and Table 2, were predicted using DeepSleepNet trained by the Wisconsin Sleep Cohort dataset. Since the number of participants were not big enough to determine whether the data was fit for parametric tests, although the data mostly assumed a normal distribution, we utilized the Friedman's two-way analysis, a non-parametric statistical test that detects differences between conditions with repeated measures. For post-hoc analysis, the Wilcoxon Sign test was administered. 


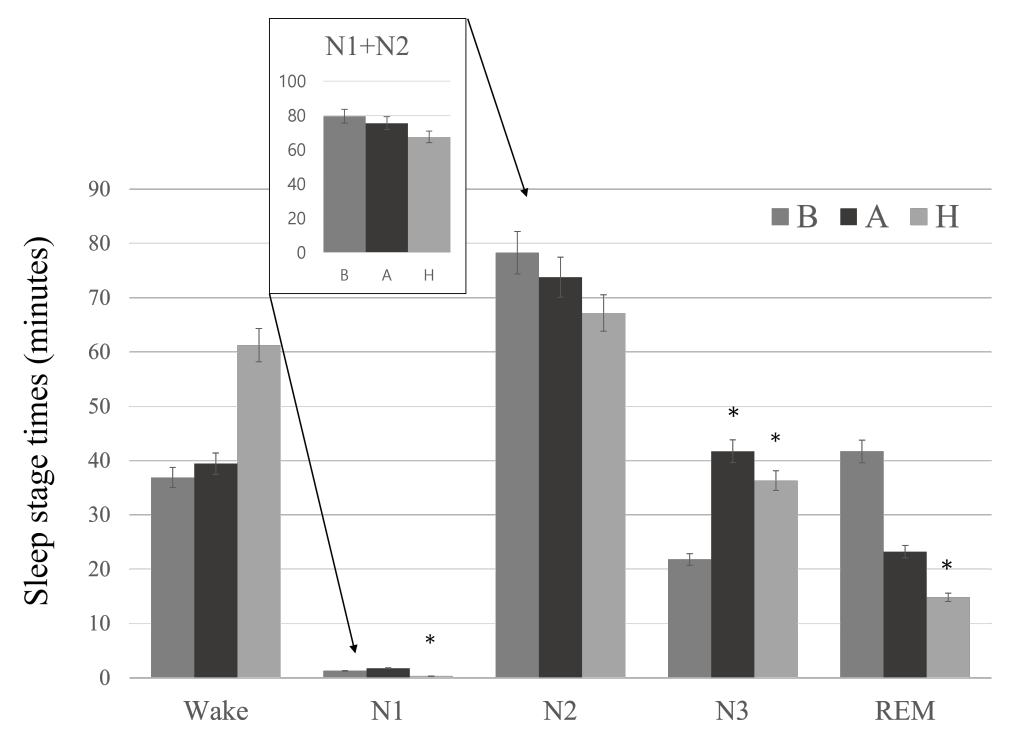

* Asterisks represent the statistical tested with Friedman two-way test between $\mathrm{B}$ and $\mathrm{A} / \mathrm{H}$ conditions significance $* \mathrm{p}<0.05$.

Figure 9. Estimated each sleep stage lengths of 15 participants during proposed nap experiments in the recliner chair.

The duration of N3 (deep sleep stage), which is measured in minutes, in Conditions $\mathrm{A}$ and $\mathrm{H}(p<0.05$ for Condition $\mathrm{A}$ and $p<0.01$ for Condition $\mathrm{H}$ tested using Friedman two-way test) are significantly higher than in Condition B, which is the control of the study.

The parameters are separated into four categories, such as 'sleep stage (min)', 'sleep stage $(\%)^{\prime}$, 'sleep latencies', and 'sleep indexes'. The sleep stage ( $\mathrm{min}$ ) is the length of each sleep stage, sleep stage (\%) is the percentage of each sleep stage length relative to the total sleep length, sleep latencies is the time length entering a particular sleep stage, and sleep indexes are the sleep parameters suggested by the American Association of Sleep Medicine (AASM) [27].

The rocking motions in condition $\mathrm{H}$ significantly shorten the length of light sleep stages shown in Figure 9 based on TN1, TN2, N1\%, and N2\%, which indicate light sleep. Meanwhile, the deep sleep-related parameters, including TN3 and SWS\%, indicate the increase of the deep sleep stage of participants in Conditions A and $\mathrm{H}$ compared to Condition B. However, the length of the REM sleep stage has decreased significantly in Condition A, indicating a possible deterioration of sleep quality of the participants. For further investigation of these seemingly contradicting results, we discuss an in-depth analysis of participants' sleep spindles, which play a bigger role in several other cognitive functions such as visual attention, selective attention, and impulse control based on various findings.

In addition, 'sleep latencies (min)', which is a major parameter in evaluating sleep quality [28], shows significantly shorter periods to get to the NREM3 stage compared to that of Condition B. However, the TST value, which is the indicator of the total amount of sleep, shows that the amount of sleep at rocking motion has decreased relatively, which is evident in Condition H. It was statistically significant that the overall amount of time and number of events about the N3 stage was increased compared to the control group. 
Table 2. Sleep parameters in each experimental condition for the whole nap time of sleep analysis; Time in Bed is calculated from light-off; TSP, TST, and sleep latencies are calculated from the first N1 period ( $>1 \mathrm{~min})$.

\begin{tabular}{|c|c|c|c|}
\hline & B Condition & A Condition & H Condition \\
\hline TIB [min] & 180 & 180 & 180 \\
\hline TSP [min] & $171.4( \pm 11.74)$ & $172.67( \pm 7.63)$ & $177.47( \pm 4.55)$ \\
\hline $\mathrm{TST}^{\star}[\mathrm{min}]$ & $143.1( \pm 42.40)$ & $140.53( \pm 25.2)$ & $118.7( \pm 42.50)$ \\
\hline \multicolumn{4}{|l|}{ Sleep Length [min] } \\
\hline $\mathrm{TN} 1(\mathrm{~N} 1)^{\star}$ & $1.3( \pm 0.99)$ & $1.77( \pm 2.82)$ & $0.33( \pm 0.48) *$ \\
\hline $\mathrm{TN} 2(\mathrm{~N} 2) \star$ & $78.3( \pm 36.42)$ & $73.8( \pm 29.92)$ & $67.2( \pm 31.57)$ \\
\hline TN3 (N3) $\star$ & $21.8( \pm 20.07)$ & $41.73(21.51) *$ & $36.33( \pm 15.20) *$ \\
\hline TN1+TN2 (Light) & $79.60( \pm 36.37)$ & $75.56( \pm 29.95)$ & $67.53( \pm 37.76)$ \\
\hline $\mathrm{TR}(\mathrm{REM}) \star$ & $41.70( \pm 43.14)$ & $23.23( \pm 34.66)$ & $14.83( \pm 29.91) *$ \\
\hline
\end{tabular}

\section{Sleep Ratio [\%]}

$\begin{array}{lccc}\mathrm{N} 1 \%(\mathrm{~N} 1) \star & 0.89( \pm 0.69) & 1.19( \pm 1.71) & \mathbf{0 . 2 4}( \pm \mathbf{0 . 4 0}) * * \\ \mathrm{~N} 2 \%(\mathrm{~N} 2)^{\star} & 55.17( \pm 25.02) & 53.26( \pm 20.26) & 56.40( \pm 15.19) \\ \mathrm{SWS} \%(\mathrm{~N} 3) \star & 18.46( \pm 20.52) & \mathbf{3 0 . 5 8}( \pm \mathbf{1 5 . 8 5}) * & \mathbf{3 4 . 0 8}( \pm \mathbf{1 5 . 1 9 )} * * \\ \mathrm{N} 1 \%+\mathrm{N} 2 \% \text { (Light) } & 56.05( \pm 25.08) & 54.45( \pm 20.02) & 56.64( \pm 15.28) \\ \mathrm{REM} \%(\mathrm{REM}) \star & 25.48( \pm 24.57) & 14.97( \pm 20.44) & \mathbf{9 . 2 7}( \pm \mathbf{1 6 . 3 0}) *\end{array}$

\section{Sleep Latencies [min]}

To Light $(\mathrm{N} 1+\mathrm{N} 2)$

$21.70( \pm 41.72)$

$21.00( \pm 9.79)$

$35.60( \pm 15.46)$

To Deep (N3)

44.43( \pm 23.85$)$

21.03( \pm 10.10$) *$

$30.23( \pm 30.58)$

To REM

$16.56( \pm 31.43)$

25.53( \pm 43.35$)$

$27.00( \pm 47.52)$

\section{Sleep Indices}

$\begin{array}{lccc}\mathrm{SL} \%[\%] & 57.54( \pm 92.86) & 72.30( \pm 69.66) & 69.15( \pm 48.79) \\ \mathrm{SOL}{ }^{\star}[\mathrm{min}] & 36.90( \pm 42.40) & 39.47( \pm 25.2) & 61.30( \pm 42.50) \\ \text { Sleep Efficiency (SE) }{ }^{\star}[\%] & 79.50( \pm 23.55) & 78.08( \pm 14.15) & 65.94( \pm 23.61)\end{array}$

$\star$ Recommended to be a reported parameter for polysomnography by the AASM Manual for the Scoring of Sleep and Associated Event, version 2.4., 2017. * Asterisks represent the statistical tested with Friedman two-way test between $\mathrm{B}$ and $\mathrm{A} / \mathrm{H}$ conditions significance ${ }^{*} p<$ 0.05 , and ${ }^{* *} p<0.01$.

\subsection{Sleep Spindle Analysis}

Sleep spindles in EEG signals were investigated as another index in assessing the sleep quality without the sleep scoring information. The spindle can be analyzed based on the total amount of time, the number of spindle events, and its density and duration. 
The results of the spindle analysis corresponding to each rocking motion condition are shown in Table 3.

Table 3. Sleep spindle analysis of EEG signals corresponding to each experimental condition during the three-hour nap

\begin{tabular}{lccc}
\hline & B Condition & A Condition & H Condition \\
\hline Number of Spindle Event & $77.43( \pm 50.76)$ & $\mathbf{1 1 3 . 9 9}( \pm \mathbf{6 6 . 3 0}) * *$ & $75.33( \pm 56.83)$ \\
Spindle Time (s) & $68.32( \pm 45.00)$ & $\mathbf{9 6 . 2 2}( \pm \mathbf{5 6 . 0 0 )} * *$ & $64.14( \pm 52.00)$ \\
Density (/30 s) & $0.2673( \pm 0.0240)$ & $\mathbf{0 . 1 8 7 9}( \pm \mathbf{0 . 0 1 5 9 )} * *$ & $0.1782( \pm 0.0207)$ \\
Duration (s) & $0.83( \pm 0.28)$ & $0.83( \pm 0.29)$ & $0.83( \pm 0.30)$ \\
\end{tabular}

\section{Fast Spindles}
Amplitude ( $\mu \mathrm{v})$
$56.29( \pm 35.50)$
$60.78( \pm 41.69)$
$65.18( \pm 59.76)$
Frequency $(\mathrm{Hz})$
$12.79( \pm 0.54)$
$12.79( \pm 0.60)$
$12.76( \pm 0.57)$

\begin{tabular}{|c|c|c|c|}
\hline Amplitude $(\mu \mathrm{v})$ & $24.24( \pm 14.50)$ & $29.41( \pm 25.60)$ & $34.47( \pm 31.18)$ \\
\hline Frequency (Hz) & $8.79( \pm 0.17)$ & $8.61( \pm 0.21)$ & $8.81( \pm 0.23)$ \\
\hline
\end{tabular}

${ }^{*}$ Asterisks represent the statistical tested with Friedman two-way test between B and A / H conditions significance ${ }^{* *} p<0.01$.

Looking at the average spindle frequencies in each condition, the quantity of sleep spindles significantly increases in Condition A. Moreover, even considering the total spindle time and its density, that is, the average recurrence of spindles in a $30 \mathrm{~s}$ period, Condition A shows more promising results. However, the sleep spindles have overall not improved for participants in Condition $\mathrm{H}$.

\subsection{Qualitative Sleep Analysis}

The results of the qualitative sleep analysis of the participants based on the selfreported survey are shown in Table 4. Results show that there were no significant difference among the rocking condition experiments based on the self-reported responses. Most of the participants reported similar sleep and awake time in all three conditions and felt longer periods of sleep than the actual ones measured qualitatively using their EEG signals. The discrepancy between the quantitative and qualitative assessments of the sleep quality has been reported in several previous studies $[98,99]$.

PSQI scores tell that assess participants' quality of sleep over one-month period, containing questions about their usual sleep habits, with scores ranging from 0 to 21 . Using the PSQI scores, participants are differentiated into two groups: one with poor sleep habits and another with good sleep habits. As suggested by Buysse et al. [57], we were set a threshold, 5, to separate 'Good Sleepers' having scores points under 5 and 'Bad Sleepers' over 5. Based on this criterion, the sleep parameters of the 'good' and 'bad' sleepers in three different experimental conditions were looked into, which are summarized in Table 5. SWS\%, TN3, and SL\% are the indicators of deep sleep and, the 'Bad Sleeper' group shows a significant increase of these parameters than the 'Good Sleepers' group. Particularly, regarding the parameters most closely related to the sleep quality, SWS\% and TN3, the 'Bad Sleeper' group has a significant increase. The self-reported sleep quality in Table 6 has no 
significant difference between the 'Good Sleeper' and the 'Bad Sleeper' groups. However, when comparing the sleep times between the groups, the 'Bad Sleeper' group has more improved results by the rocking motions than the 'Good Sleeper' group.

Table 4. Self-reported sleep quality after the nap of the participants in three experimental conditions.

\begin{tabular}{lccc}
\hline & B Condition & A Condition & H Condition \\
\hline Time in Bed (min) & 180 & 180 & 180 \\
\hline Self-reported Survey Results & & & $9.60( \pm 5.78)$ \\
Sleep Latency (min) & $13.13( \pm 10.29)$ & $12.53( \pm 7.92)$ & $31.87( \pm 16.91)$ \\
Wake Time (min) & $30.67( \pm 19.22)$ & $28.93( \pm 15.31)$ & $148.13( \pm 16.91)$ \\
Sleep Time (min) & $149.33( \pm 19.22)$ & $151.07( \pm 15.31)$ & $0.82( \pm 0.09)$ \\
SE (Sleep Efficiency) & $0.83( \pm 0.11)$ & $0.84( \pm 0.06)$ & \\
\hline
\end{tabular}

Table 5. Comparison of the quantitative sleep parameters between two groups separated by PSQI levels 'Good Sleeper' and 'Bad Sleeper'.

\begin{tabular}{|c|c|c|c|c|}
\hline & & B Condition & A Condition & H Condition \\
\hline Good Sleeper & $\mathrm{SL} \%$ & $0.82( \pm 1.15)$ & $0.60( \pm 0.49)$ & $0.73( \pm 0.51)$ \\
\hline$(\mathrm{PSQI}<5)$ & SWS $\% \star$ & $0.25( \pm 0.24)$ & $0.28( \pm 0.12)$ & $0.35( \pm 0.15) *$ \\
\hline 9 subject & $\mathrm{TN} 3(\min ) \star$ & $27.72( \pm 23.56)$ & $39.06( \pm 14.20)$ & $37.22( \pm 18.08)$ \\
\hline Bad Sleeper & $\mathrm{SL} \%$ & $0.21( \pm 0.17)$ & $0.91( \pm 0.95)$ & $0.61( \pm 0.50)$ \\
\hline$(\mathrm{PSQI} \geq 5)$ & SWS $\% \star$ & $0.09( \pm 0.06)$ & $0.34( \pm 0.22) *$ & $0.32( \pm 0.14) *$ \\
\hline 6 subject & $\mathrm{TN} 3(\min ) \star$ & $12.92( \pm 9.04)$ & $45.75( \pm 30.67) *$ & $35.00( \pm 11.00) *$ \\
\hline
\end{tabular}

$\star$ Recommended to be a reported parameter for polysomnography by the AASM Manual for the Scoring of Sleep and Associated Event, version 2.4., 2017. * Asterisks represent the statistical tested with Friedman two-way test between B and A / H conditions significance * $p$ $<0.05$.

Table 6. Comparison of the reported self-reported sleep quality between two sleep type groups 'Good Sleeper'.

\begin{tabular}{|c|c|c|c|c|}
\hline & & B Condition & A Condition & H Condition \\
\hline $\begin{array}{l}\text { Good Sleeper } \\
(\text { PSQI < 5) }\end{array}$ & $\begin{array}{l}\text { Latency } \\
(\mathrm{min})\end{array}$ & $15.56( \pm 12.10)$ & $15.33( \pm 9.14)$ & $9.22( \pm 4.09)$ \\
\hline 9 subject & $\begin{array}{l}\text { Sleep time } \\
\text { (min) }\end{array}$ & $154.44( \pm 18.37)$ & $148.22( \pm 17.09)$ & $147.22( \pm 16.41)$ \\
\hline $\begin{array}{l}\text { Bad Sleeper } \\
\text { (PSQI } \geq 5)\end{array}$ & $\begin{array}{l}\text { Latency } \\
(\mathrm{min})\end{array}$ & $9.50( \pm 5.96)$ & $8.33( \pm 2.58)$ & $10.17( \pm 8.13)$ \\
\hline 6 subject & $\begin{array}{l}\text { Sleep time } \\
(\mathrm{min})\end{array}$ & $141.67( \pm 19.41)$ & $155.33( \pm 12.36)$ & $149.50( \pm 19.11)$ \\
\hline
\end{tabular}

\section{Discussion}

As we can see in Table 2, there were significant increase of the amount of deep sleep (N3) in condition A and $\mathrm{H}$. In addition, the significant decrease of N1 stage is confirmed in condition $\mathrm{H}$. The decrease of light sleep and the increase of deep sleep could infer 
the improvement of sleep quality [28]. The decrease of sleep latency to deep stage in condition A (see Table 2), indicates that the rocking motions could help extend the period of the deep sleep stage by reducing the time to reach the deep sleep phase. These results demonstrated that the rocking motions of the recliner could enhance the length of the deep sleep stage. The results are consistent with the previous reports by Omlin et al. [39] and Perrault et al. [100], demonstrating that the rocking motion increased the proportion of deep sleep stages among all-night sleep stages. Thus, this result proved that the deep latency caused by the rocking motion was significantly decreased during the three hours of the short nap on the recliner. Several previous studies reported that increasing the length of deep sleep stages, which is one of the key indicators of the improvement of sleep quality denoted by TN3, is effective in regenerating the body [101-103] and strengthening immunity [104-106]. In addition, the investigation of the sleep parameters is considered as an additional quantitative sleep quality analysis corresponding to the three different recliner conditions shown in Table 2. Furthermore, we conducted the analysis the sleep quality using the 11 sleep parameters listed in Figure 7 for a more accurate quantitative analysis. The results of the quantitative analysis based on the sleep parameters in determining sleep quality using the automated sleep scoring algorithm are shown in Table 2.

A separate sleep analysis was conducted from the participants who were relatively exposed to the risk of sleep disorders with low sleep quality based on PSQI scores in Table 6. As a result, more significant improvement of N3 sleep stage (deep sleep) could be confirmed in the participant group with low sleep quality, and Table 6 also demonstrated that the improvement in an increase of N3 sleep stage in the 'Bad Sleeper' group was bigger than that in the 'Good Sleeper' group. Thus, it confirmed that sleep in the recliner with a rocking motion such as Condition $\mathrm{H}$ was more effective in improving the quality of sleep for the people who have poor sleep habits. Therefore, the rocking motions proposed in this paper could help the people with high PSQI scores to induce high quality of their sleep. In addition, for those with a relatively high risk of sleep disorders, it would have a positive impact on the improvement of the sleep quality with the proposed rocking motion. Previous studies reported that those with high PSQI scores ('Bad Sleeper') are more likely to develop depressive symptoms and might be more susceptible to dementia and other cognitive impairments [107-110]. Therefore, we suggest that more sleep in the rocking motion might prevent these diseases.

In this study, sleep experiments and its analysis with sleep stage and spindles were conducted only using the two-channel brain waves, which is different from the conventional polysomnography (PSG) method that uses multimodal sensors such as multichannel EEG, electromyogram (EMG), electrocardiogram (ECG), and respiration to score the sleep stages. Despite that, there were multiple studies that produced significant and robust sleep scoring results [111]. Moreover, several studies have demonstrated that a generalized sleep scoring model based on a single or multi-channel brainwave produced similar sleep stages as those by sleep experts $[60,61,87]$.

The substantial long-term memory conversion and task memory enhancement during the spindle event have been reported previously [76,112]. Omlin et al. [39] and Perrault et al. [100] demonstrated that the rocking motion induced the enhancement of spindles. In Table 3, the sleep spindle analysis using the EEG signals also confirms that the rocking motion of Condition A induces more spindle occurrences and increases its amount during the nap. Since this increase of the spindle is known to reinforce positive sleep effects, such as long-term memory conversion for learning and memory [32,33], motor ability $[113,114]$ and sensory shut down for reducing wake up $[34,35]$, it could be suggested that the sleep in Condition H would significantly improved the mental ability. Especially, considering the previous studies reporting that the spindle could have a positive effect on implicit and explicit memory consolidation [73-77], it is expected that the recliner chair with the suggested rocking motions could improve the performance of the brain. However, the memory test of the participant after the nap was not included since the enhanced spindles by the rocking motion during the nap were not expected when designing the 
experiment initially. In addition, Table 3 shows the amplitude and frequency of the two different types of spindles, fast and slow spindle [38], where each of the two different types of spindles was consistently estimated from the reliable EEG signals based on the corresponding standard range of two spindles [33,37,38]. In the following studies, the effect of the rocking motions on the memory enhancement will be mainly investigated. Furthermore, multi-channel EEG signals will be recorded to apply the multivariate algorithms in order to extract the spindle component accurately, which could be blind source separation algorithms [115-117].

In Table 4, we conducted an analysis of qualitative sleep quality based on a survey from the participants. Unlike the quantitative sleep analysis, the results demonstrated that there was no clear difference among the subjects. The difference between these qualitative and quantitative sleep analysis results in evaluating the sleep quality has been reported several times in the other studies [118-122]. Considering the environment of this experiment might be unfamiliar to the participants even though the first night sleep effect [54] was considered and that the sleep duration of the participants was limited during the experiment, the subjective feedback from the participants in a qualitative level might have been affected.

\section{Conclusions}

In this study, we investigated the influence of rocking motions on sleep quality during a nap. The sleep parameter analysis has proved that rocking motions improve the sleep quality by increasing the amount of N3 (Deep Sleep) sleep stage, and especially in the proposed Condition A the rocking motion provides a significantly positive effect on the spindle enhancement. These could be indicators of an efficient sleep experience even during the short period of nap. In addition, in an analysis based on the PSQI scores, it was confirmed that the Rocking motion improves the sleep quality more effectively for the 'Bad Sleeper' group, who would be exposed to the risk of sleep disorders. Furthermore, these rocking motion paradigms could be extended to night-time sleep, which encompasses six hours of sleep, that keeps the body in good conditions.

Author Contributions: Conceptualization, S.B., H.Y. and J.R.; data curation, H.Y.; formal analysis, S.B., J.L. and I.S.; funding acquisition, H.Y.; investigation, J.L.; methodology, S.B., J.R. and J.L.; resources, J.R.; software, S.B.; supervision, S.K. and C.P.; validation, S.B. and H.Y.; writing-original draft, S.B. and H.Y.; writing - review and editing, I.S., S.K. and C.P. All authors have read and agreed to the published version of the manuscript.

Funding: This work was supported by the National Research Foundation of Korea (NRF) grant funded by the Korea government (MSIT) (NRF-2017R1A5A1015596), the Ministry of Trade, Industry and Energy (MOTIE), Korea as "Product and service design of recliner chair including smart life care service (20007942), and the Excellent researcher support project of Kwangwoon University in 2021.

Institutional Review Board Statement: This experiment was approved by the Institutional Review Board of Kwangwoon University (IRB No. 7001546-20200728-HR(SB)-006-01).

Informed Consent Statement: Written informed consent has been obtained from the patient(s) to publish this paper.

Data Availability Statement: Not applicable.

Acknowledgments: This work was supported by the National Research Foundation of Korea (NRF) grant funded by the Korea government (MSIT) (NRF-2017R1A5A1015596), the Ministry of Trade, Industry and Energy (MOTIE), Korea as "Product and service design of recliner chair including smart life care service (20007942), and the Excellent researcher support project of Kwangwoon University in 2021.

Conflicts of Interest: The authors declare no conflict of interest. 


\section{References}

1. Härmä, M. Ageing, physical fitness and shiftwork tolerance. Appl. Ergon. 1996, 27, 25-29. [CrossRef]

2. Shepard, J.W.; Buysse, D.J.; Chesson, A.L.; Dement, W.C.; Goldberg, R.; Guilleminault, C.; Harris, C.D.; Iber, C.; Mignot, E.; Mitler, M.M.; et al. History of the development of sleep medicine in the United States. J. Clin. Sleep Med. 2005, 1, 61-82. [CrossRef]

3. Hsu, H.C.; Lin, M.H. Exploring quality of sleep and its related factors among menopausal women. J. Nurs. Res. JNR 2005, 13, 153-164. [CrossRef]

4. Pilcher, J.J.; Ginter, D.R.; Sadowsky, B. Sleep quality versus sleep quantity: Relationships between sleep and measures of health, well-being and sleepiness in college students. J. Psychosom. Res. 1997, 42, 583-596. [CrossRef]

5. Iliescu, E.A.; Coo, H.; McMurray, M.H.; Meers, C.L.; Quinn, M.M.; Singer, M.A.; Hopman, W.M. Quality of sleep and health-related quality of life in haemodialysis patients. Nephrol. Dial. Transplant. 2003, 18, 126-132. [CrossRef]

6. $\quad$ LeBourgeois, M.K.; Giannotti, F.; Cortesi, F.; Wolfson, A.R.; Harsh, J. The relationship between reported sleep quality and sleep hygiene in Italian and American adolescents. Pediatrics 2005, 115, 257-265. [CrossRef]

7. Léger, D.; Guilleminault, C.; Bader, G.; Lévy, E.; Paillard, M. Medical and socio-professional impact of insomnia. Sleep 2002, 25, 621-625. [CrossRef]

8. Medic, G.; Wille, M.; Hemels, M.E. Short-and long-term health consequences of sleep disruption. Nat. Sci. Sleep 2017, 9, 151. [CrossRef] [PubMed]

9. Womack, S.D.; Hook, J.N.; Reyna, S.H.; Ramos, M. Sleep loss and risk-taking behavior: A review of the literature. Behav. Sleep Med. 2013, 11, 343-359. [CrossRef]

10. Terzano, M.G.; Parrino, L.; Cirignotta, F.; Ferini-Strambi, L.; Gigli, G.; Rudelli, G.; Sommacal, S. Studio Morfeo: Insomnia in primary care, a survey conducted on the Italian population. Sleep Med. 2004, 5, 67-75. [CrossRef]

11. Ganz, F.D. Sleep and immune function. Crit. Care Nurse 2012, 32, e19-e25. [CrossRef]

12. Michal, M.; Wiltink, J.; Kirschner, Y.; Schneider, A.; Wild, P.S.; Münzel, T.; Blettner, M.; Schulz, A.; Lackner, K.; Pfeiffer, N.; et al. Complaints of sleep disturbances are associated with cardiovascular disease: Results from the Gutenberg Health Study. PLoS ONE 2014, 9, e104324.

13. Hayashi, M.; Ito, S.; Hori, T. The effects of a 20-min nap at noon on sleepiness, performance and EEG activity. Int. J. Psychophysiol. 1999, 32, 173-180. [CrossRef]

14. Andrechuk, C.R.S.; Ceolim, M.F. Sleep quality and adverse outcomes for patients with acute myocardial infarction. J. Clin. Nurs. 2016, 25, 223-230. [CrossRef]

15. BaHammam, A. Sleep quality of patients with acute myocardial infarction outside the CCU environment: A preliminary study. Med. Sci. Monit. 2006, 12, CR168-CR172.

16. Fredriksson-Larsson, U.; Alsén, P.; Karlson, B.W.; Brink, E. Fatigue two months after myocardial infarction and its relationships with other concurrent symptoms, sleep quality and coping strategies. J. Clin. Nurs. 2015, 24, 2192-2200. [CrossRef]

17. Adams, S.K.; Kisler, T.S. Sleep quality as a mediator between technology-related sleep quality, depression, and anxiety. Cyberpsychol. Behav. Soc. Netw. 2013, 16, 25-30. [CrossRef]

18. Demirci, K.; Akgönül, M.; Akpinar, A. Relationship of smartphone use severity with sleep quality, depression, and anxiety in university students. J. Behav. Addict. 2015, 4, 85-92. [CrossRef]

19. Ness, T.E.B.; Saksvik-Lehouillier, I. The relationships between life satisfaction and sleep quality, sleep duration and variability of sleep in university students. J. Eur. Psychol. Stud. 2018, 9, 28-39 [CrossRef]

20. Nicholson, A.; Stone, B.M. Influence of back angle on the quality of sleep in seats. Ergonomics 1987, 30, 1033-1041. [CrossRef]

21. Roach, G.D.; Matthews, R.; Naweed, A.; Kontou, T.G.; Sargent, C. Flat-out napping: The quantity and quality of sleep obtained in a seat during the daytime increase as the angle of recline of the seat increases. Chronobiol. Int. 2018, 35, 872-883. [CrossRef]

22. McEvoy, R.D.; Sharp, D.J.; Thornton, A.T. The effects of posture on obstructive sleep apnea. Am. Rev. Respir. Dis. 1986, $133,662-666$.

23. Martin, S.E.; Marshall, I.; Douglas, N.J. The effect of posture on airway caliber with the sleep-apnea/hypopnea syndrome. Am. J. Respir. Crit. Care Med. 1995, 152, 721-724. [CrossRef] [PubMed]

24. Neill, A.M.; Angus, S.M.; Sajkov, D.; McEVOY, R.D. Effects of sleep posture on upper airway stability in patients with obstructive sleep apnea. Am. J. Respir. Crit. Care Med. 1997, 155, 199-204. [CrossRef] [PubMed]

25. de Barros Souza, F.J.F.; Genta, P.R.; de Souza Filho, A.J.; Wellman, A.; Lorenzi-Filho, G. The influence of head-of-bed elevation in patients with obstructive sleep apnea. Sleep Breath. 2017, 21, 815-820. [CrossRef] [PubMed]

26. Khan, B.A.; Sodhi, J.S.; Zargar, S.A.; Javid, G.; Yattoo, G.N.; Shah, A.; Gulzar, G.M.; Khan, M.A. Effect of bed head elevation during sleep in symptomatic patients of nocturnal gastroesophageal reflux. J. Gastroenterol. Hepatol. 2012, 27, 1078-1082. [CrossRef] [PubMed]

27. Berry, R.B.; Brooks, R.; Gamaldo, C.E.; Harding, S.M.; Marcus, C.; Vaughn, B.V. The AASM manual for the scoring of sleep and associated events. Rules Terminol. Tech. Specif. Darien Ill. Am. Acad. Sleep Med. 2012, 176, 2012.

28. Mendonça, F.; Mostafa, S.S.; Morgado-Dias, F.; Ravelo-Garcia, A.G.; Penzel, T. A review of approaches for sleep quality analysis. IEEE Access 2019, 7, 24527-24546. [CrossRef]

29. De Gennaro, L.; Ferrara, M. Sleep spindles: An overview. Sleep Med. Rev. 2003, 7, 423-440. [CrossRef] [PubMed]

30. Berry, R.B.; Wagner, M.H. Sleep Medicine Pearls E-Book; Elsevier Health Sciences: Amsterdam, The Netherlands, 2014. 
31. JSSR; Hori, T.; Sugita, Y.; Koga, E.; Shirakawa, S.; Inoue, K.; Uchida, S.; Kuwahara, H.; Kousaka, M.; Kobayashi, T.; et al. Proposed supplements and amendments to 'A manual of standardized terminology, techniques and scoring system for sleep stages of human subjects', the Rechtschaffen \& Kales (1968) standard. Psychiatry Clin. Neurosci. 2001, 55, 305-310.

32. Fogel, S.M.; Smith, C.T. The function of the sleep spindle: A physiological index of intelligence and a mechanism for sleepdependent memory consolidation. Neurosci. Biobehav. Rev. 2011, 35, 1154-1165. [CrossRef] [PubMed]

33. Hennies, N.; Ralph, M.A.L.; Kempkes, M.; Cousins, J.N.; Lewis, P.A. Sleep spindle density predicts the effect of prior knowledge on memory consolidation. J. Neurosci. 2016, 36, 3799-3810. [CrossRef]

34. Schönauer, M.; Pöhlchen, D. Sleep spindles. Curr. Biol. 2018, 28, R1129-R1130. [CrossRef] [PubMed]

35. Lüthi, A. Sleep spindles: Where they come from, what they do. Neuroscientist 2014, 20, 243-256. [CrossRef]

36. Jarrin, D.C.; McGrath, J.J.; Silverstein, J.E.; Drake, C. Objective and subjective socioeconomic gradients exist for sleep quality, sleep latency, sleep duration, weekend oversleep, and daytime sleepiness in adults. Behav. Sleep Med. 2013, 11, 144-158. [CrossRef] [PubMed]

37. Cox, R.; Schapiro, A.C.; Manoach, D.S.; Stickgold, R. Individual differences in frequency and topography of slow and fast sleep spindles. Front. Hum. Neurosci. 2017, 11, 433. [CrossRef] [PubMed]

38. Mölle, M.; Bergmann, T.O.; Marshall, L.; Born, J. Fast and slow spindles during the sleep slow oscillation: Disparate coalescence and engagement in memory processing. Sleep 2011, 34, 1411-1421. [CrossRef]

39. Omlin, X.; Crivelli, F.; Näf, M.; Heinicke, L.; Skorucak, J.; Malafeev, A.; Guerrero, A.F.; Riener, R.; Achermann, P. The effect of a slowly rocking bed on sleep. Sci. Rep. 2018, 8, 1-10. [CrossRef] [PubMed]

40. Crivelli, F.; Omlin, X.; Rauter, G.; Von Zitzewitz, J.; Achermann, P.; Riener, R. Somnomat: A novel actuated bed to investigate the effect of vestibular stimulation. Med. Biol. Eng. Comput. 2016, 54, 877-889. [CrossRef] [PubMed]

41. Hayashi, M.; Abe, A. Short daytime naps in a car seat to counteract daytime sleepiness: The effect of backrest angle. Sleep Biol. Rhythm. 2008, 6, 34-41. [CrossRef]

42. Buysse, D.J.; Reynolds III, C.F.; Monk, T.H.; Hoch, C.C.; Yeager, A.L.; Kupfer, D.J. Quantification of subjective sleep quality in healthy elderly men and women using the Pittsburgh Sleep Quality Index (PSQI). Sleep 1991, 14, 331-338. [PubMed]

43. Cho, C.H.; Yoon, H.K.; Kang, S.G.; Kim, L.; Lee, E.I.; Lee, H.J. Impact of exposure to dim light at night on sleep in female and comparison with male subjects. Psychiatry Investig. 2018, 15, 520. [CrossRef] [PubMed]

44. Öhrström, E.; Skånberg, A. Sleep disturbances from road traffic and ventilation noise-laboratory and field experiments. J. Sound Vib. 2004, 271, 279-296. [CrossRef]

45. Berglund, B.; Lindvall, T. Community Noise; Center for Sensory Research, Stockholm University and Karolinska Institute: Stockholm, Sweden, 1995.

46. Caddick, Z.A.; Gregory, K.; Arsintescu, L.; Flynn-Evans, E.E. A review of the environmental parameters necessary for an optimal sleep environment. Build. Environ. 2018, 132, 11-20. [CrossRef]

47. Krishnan, K.K.; Soman, K. CNN based classification of motor imaginary using variational mode decomposed EEG-spectrum image. Biomed. Eng. Lett. 2021, 11, 1-13. [CrossRef] [PubMed]

48. Sheng, H.; Chen, Y.; Qiu, T. Multifractional Property Analysis of Human Sleep Electroencephalogram Signals. In Fractional Processes and Fractional-Order Signal Processing: Techniques and Applications; Springer: London, UK, 2012; pp. 243-250._13. [CrossRef]

49. Casson, A.J. Wearable EEG and beyond. Biomed. Eng. Lett. 2019, 9, 53-71. [CrossRef] [PubMed]

50. Kim, N.; Seo, W.; Kim, S.; Park, S.M. Electrogastrogram: Demonstrating Feasibility in Mental Stress Assessment Using Sensor Fusion. IEEE Sens. J. 2021, 21, 14503-14514. [CrossRef]

51. Brito, M.A.; Li, D.; Mashour, G.A.; Pal, D. State-dependent and bandwidth-specific effects of ketamine and propofol on electroencephalographic complexity in rats. Front. Syst. Neurosci. 2020, 14, 50. [CrossRef]

52. Lee, H.; Kim, G.; Kim, J.; Kang, Y.; Park, C. Optimal Design of Convolutional Neural Network for EEG-based Authentication. IEIE Trans. Smart Process. Comput. 2021, 10, 199-203. [CrossRef]

53. Piskorowski, J. Digital notch filter with time-varying quality factor for the reduction of powerline interference. In Proceedings of the 2010 IEEE International Symposium on Circuits and Systems, Paris, France, 30 May-2 June 2010; pp. $2706-2709$.

54. Agnew Jr, H.; Webb, W.B.; Williams, R.L. The first night effect: An Eeg studyof sleep. Psychophysiology 1966, 2, 263-266. [CrossRef] [PubMed]

55. Morley, A.; Hill, L.; Kaditis, A. 10-20 System EEG Placement; European Respiratory Society, European Respiratory Society:Lausanne, Brussels and Sheffield, 2016.

56. Gutmann, B.; Mierau, A.; Hülsdünker, T.; Hildebrand, C.; Przyklenk, A.; Hollmann, W.; Strüder, H.K. Effects of physical exercise on individual resting state EEG alpha peak frequency. Neural Plast. 2015, 2015, 717312. [CrossRef] [PubMed]

57. Buysse, D.J.; Reynolds III, C.F.; Monk, T.H.; Berman, S.R.; Kupfer, D.J. The Pittsburgh Sleep Quality Index: A new instrument for psychiatric practice and research. Psychiatry Res. 1989, 28, 193-213. [CrossRef]

58. Åkerstedt, T.; Gillberg, M. Subjective and objective sleepiness in the active individual. Int. J. Neurosci. 1990, 52, 29-37. [CrossRef] [PubMed]

59. Whitney, C.W.; Gottlieb, D.J.; Redline, S.; Norman, R.G.; Dodge, R.R.; Shahar, E.; Surovec, S.; Nieto, F.J. Reliability of scoring respiratory disturbance indices and sleep staging. Sleep 1998, 21, 749-757. [CrossRef] [PubMed] 
60. Lacourse, K.; Delfrate, J.; Beaudry, J.; Peppard, P.; Warby, S.C. A sleep spindle detection algorithm that emulates human expert spindle scoring. J. Neurosci. Methods 2019, 316, 3-11. [CrossRef] [PubMed]

61. Vallat, R.; Walker, M.P. A universal, open-source, high-performance tool for automated sleep staging. bioRxiv 2021. . [CrossRef]

62. Supratak, A.; Dong, H.; Wu, C.; Guo, Y. DeepSleepNet: A model for automatic sleep stage scoring based on raw single-channel EEG. IEEE Trans. Neural Syst. Rehabil. Eng. 2017, 25, 1998-2008. [CrossRef] [PubMed]

63. Zhang, G.Q.; Cui, L.; Mueller, R.; Tao, S.; Kim, M.; Rueschman, M.; Mariani, S.; Mobley, D.; Redline, S. The National Sleep Research Resource: Towards a sleep data commons. J. Am. Med. Inform. Assoc. 2018, 25, 1351-1358. [CrossRef] [PubMed]

64. Young, T.; Palta, M.; Dempsey, J.; Peppard, P.E.; Nieto, F.J.; Hla, K.M. Burden of sleep apnea: Rationale, design, and major findings of the Wisconsin Sleep Cohort study. WMJ 2009, 108, 246.

65. Schmidhuber, J. Deep learning in neural networks: An overview. Neural Netw. 2015, 61, 85-117. [CrossRef] [PubMed]

66. Seo, W.; Kim, N.; Kim, S.; Lee, C.; Park, S.M. Deep ECG-respiration network (DeepER net) for recognizing mental stress. Sensors 2019, 19, 3021. [CrossRef]

67. Senyurek, V.Y.; Imtiaz, M.H.; Belsare, P.; Tiffany, S.; Sazonov, E. A CNN-LSTM neural network for recognition of puffing in smoking episodes using wearable sensors. Biomed. Eng. Lett. 2020, 10, 195-203. [CrossRef] [PubMed]

68. Goh, Y.H.; Ho, Z.J.; Ng, C.H.; Goh, Y.L. Enhanced CNN-based plant growing-stage classification using additional information carried in an additional channel. IEIE Trans. Smart Process. Comput. 2019, 8, 171-177. [CrossRef]

69. Han, S.; Lee, W.; Eom, H.; Kim, J.; Park, C. Detection of arrhythmia using 1D convolution neural network with LSTM model. IEIE Trans. Smart Process. Comput. 2020, 9, 261-265. [CrossRef]

70. Venkatramaphanikumar, S.; Bhattacharyya, D. Review on the Usage of Deep Learning Models in Multi-modal Sentiment Analysis. IEIE Trans. Smart Process. Comput. 2020, 9, 435-444.

71. Kingma, D.P.; Ba, J. Adam: A method for stochastic optimization. arXiv 2014, arXiv:1412.6980.

72. Chatburn, A.; Coussens, S.; Lushington, K.; Kennedy, D.; Baumert, M.; Kohler, M. Sleep spindle activity and cognitive performance in healthy children. Sleep 2013, 36, 237-243. [CrossRef] [PubMed]

73. Schabus, M.; Gruber, G.; Parapatics, S.; Sauter, C.; Klösch, G.; Anderer, P.; Klimesch, W.; Saletu, B.; Zeitlhofer, J. Sleep spindles and their significance for declarative memory consolidation. Sleep 2004, 27, 1479-1485. [CrossRef] [PubMed]

74. Clemens, Z.; Fabó, D.; Halász, P. Overnight verbal memory retention correlates with the number of sleep spindles. Neuroscience 2005, 132, 529-535. [CrossRef] [PubMed]

75. Lustenberger, C.; Wehrle, F.; Tüshaus, L.; Achermann, P.; Huber, R. The multidimensional aspects of sleep spindles and their relationship to word-pair memory consolidation. Sleep 2015, 38, 1093-1103. [CrossRef]

76. Ulrich, D. Sleep spindles as facilitators of memory formation and learning. Neural Plast. 2016, 2016. [CrossRef]

77. Cairney, S.A.; El Marj, N.; Staresina, B.P. Memory consolidation is linked to spindle-mediated information processing during sleep. Curr. Biol. 2018, 28, 948-954. [CrossRef] [PubMed]

78. Farmer, C.A.; Chilakamarri, P.; Thurm, A.E.; Swedo, S.E.; Holmes, G.L.; Buckley, A.W. Spindle activity in young children with autism, developmental delay, or typical development. Neurology 2018, 91, e112-e122. [CrossRef] [PubMed]

79. Merikanto, I.; Kuula, L.; Makkonen, T.; Salmela, L.; Räikkönen, K.; Pesonen, A.K. Autistic traits are associated with decreased activity of fast sleep spindles during adolescence. J. Clin. Sleep Med. 2019, 15, 401-407. [CrossRef]

80. Latreille, V.; Carrier, J.; Lafortune, M.; Postuma, R.B.; Bertrand, J.A.; Panisset, M.; Chouinard, S.; Gagnon, J.F. Sleep spindles in Parkinson's disease may predict the development of dementia. Neurobiol. Aging 2015, 36, 1083-1090. [CrossRef] [PubMed]

81. Kam, K.; Parekh, A.; Sharma, R.A.; Andrade, A.; Lewin, M.; Castillo, B.; Bubu, O.M.; Chua, N.J.; Miller, M.D.; Mullins, A.E.; et al. Sleep oscillation-specific associations with Alzheimer's disease CSF biomarkers: Novel roles for sleep spindles and tau. Mol. Neurodegener. 2019, 14, 1-12. [CrossRef] [PubMed]

82. Wendt, S.L.; Welinder, P.; Sorensen, H.B.; Peppard, P.E.; Jennum, P.; Perona, P.; Mignot, E.; Warby, S.C. Inter-expert and intra-expert reliability in sleep spindle scoring. Clin. Neurophysiol. 2015, 126, 1548-1556. [CrossRef]

83. Uygun, D.S.; Katsuki, F.; Bolortuya, Y.; Aguilar, D.D.; McKenna, J.T.; Thankachan, S.; McCarley, R.W.; Basheer, R.; Brown, R.E.; Strecker, R.E.; et al. Validation of an automated sleep spindle detection method for mouse electroencephalography. Sleep 2019, 42, zsy218. [CrossRef] [PubMed]

84. Sinha, R.K. Artificial neural network and wavelet based automated detection of sleep spindles, REM sleep and wake states. J. Med. Syst. 2008, 32, 291-299. [CrossRef] [PubMed]

85. Parekh, A.; Selesnick, I.W.; Osorio, R.S.; Varga, A.W.; Rapoport, D.M.; Ayappa, I. Multichannel sleep spindle detection using sparse low-rank optimization. J. Neurosci. Methods 2017, 288, 1-16. [CrossRef]

86. Chambon, S.; Thorey, V.; Arnal, P.J.; Mignot, E.; Gramfort, A. A deep learning architecture to detect events in EEG signals during sleep. In Proceedings of the 2018 IEEE 28th International Workshop on Machine Learning for Signal Processing (MLSP), Aalborg, Denmark, 17-20 September, 2018; pp. 1-6.

87. Vallat, R.; Walker, M.P. An open-source, high-performance tool for automated sleep staging. Elife 2021, 10, e70092. [CrossRef]

88. Hannesson, H.K. Evaluation of an Accessible Automatic Sleep Spindle Detector. Frontiers in Human Neuroscience, Aalborg, Switzerland, 2015, 9, pp353, Ph.D. Thesis.

89. Sejdić, E.; Djurović, I.; Jiang, J. Time-frequency feature representation using energy concentration: An overview of recent advances. Digit. Signal Process. 2009, 19, 153-183. [CrossRef] 
90. Benesty, J.; Chen, J.; Huang, Y.; Cohen, I. Pearson correlation coefficient. In Noise Reduction in Speech Processing; Springer: Berlin/Heidelberg, Germany, 2009; pp. 1-4.

91. Lim, Y.; Parker, S. FIR filter design over a discrete powers-of-two coefficient space. IEEE Trans. Acoust. Speech Signal Process. 1983, 31, 583-591.

92. Choi, S.H.; Kwon, H.B.; Jin, H.W.; Yoon, H.; Lee, M.H.; Lee, Y.J.; Park, K.S. Long Short-Term Memory Networks for Unconstrained Sleep Stage Classification Using Polyvinylidene Fluoride Film Sensor. IEEE J. Biomed. Health Inform. 2020, 24, $3606-3615$. [CrossRef] [PubMed]

93. Wei, Y.; Qi, X.; Wang, H.; Liu, Z.; Wang, G.; Yan, X. A Multi-Class Automatic Sleep Staging Method Based on Long Short-Term Memory Network Using Single-Lead Electrocardiogram Signals. IEEE Access 2019, 7, 85959-85970. [CrossRef]

94. Geng, D.; Yang, D.; Cai, M.; Zheng, L. A novel microwave treatment for sleep disorders and classification of sleep stages using multi-scale entropy. Entropy 2020, 22, 347. [CrossRef] [PubMed]

95. Zhang, Y.; Yang, Z.; Lan, K.; Liu, X.; Zhang, Z.; Li, P.; Cao, D.; Zheng, J.; Pan, J. Sleep Stage Classification Using Bidirectional LSTM in Wearable Multi-sensor Systems. IEEE Conf. Comput. Commun. Work. 2019, 443-448. [CrossRef]

96. Huang, C.S.; Lin, C.L.; Ko, L.W.; Liu, S.Y.; Sua, T.P.; Lin, C.T. A hierarchical classification system for sleep stage scoring via forehead EEG signals. In Proceedings of the 2013 IEEE Symposium on Computational Intelligence, Cognitive Algorithms, Mind, and Brain (CCMB), Singapore, 16-19 April 2013; pp. 1-5. [CrossRef]

97. Penzel, T.; Kantelhardt, J.W.; Grote, L.; Peter, J.H.; Bunde, A. Comparison of detrended fluctuation analysis and spectral analysis for heart rate variability in sleep and sleep apnea. IEEE Trans. Biomed. Eng. 2003, 50, 1143-1151. [CrossRef] [PubMed]

98. Jackowska, M.; Dockray, S.; Hendrickx, H.; Steptoe, A. Psychosocial factors and sleep efficiency: Discrepancies between subjective and objective evaluations of sleep. Psychosom. Med. 2011, 73, 810-816. [CrossRef]

99. Most, E.I.; Aboudan, S.; Scheltens, P.; Van Someren, E.J. Discrepancy between subjective and objective sleep disturbances in early-and moderate-stage Alzheimer disease. Am. J. Geriatr. Psychiatry 2012, 20, 460-467. [CrossRef]

100. Perrault, A.A.; Khani, A.; Quairiaux, C.; Kompotis, K.; Franken, P.; Muhlethaler, M.; Schwartz, S.; Bayer, L. Whole-night continuous rocking entrains spontaneous neural oscillations with benefits for sleep and memory. Curr. Biol. 2019, $29,402-411$. [CrossRef]

101. Mônico-Neto, M.; Dáttilo, M.; Ribeiro, D.A.; Lee, K.S.; de Mello, M.T.; Tufik, S.; Antunes, H.K.M. REM sleep deprivation impairs muscle regeneration in rats. Growth Factors 2017, 35, 12-18. [CrossRef]

102. Chennaoui, M.; Vanneau, T.; Trignol, A.; Arnal, P.; Gomez-Merino, D.; Baudot, C.; Perez, J.; Pochettino, S.; Eirale, C.; Chalabi, H. How does sleep help recovery from exercise-induced muscle injuries? J. Sci. Med. Sport 2021.. [CrossRef] [PubMed]

103. Eide, P.K.; Vinje, V.; Pripp, A.H.; Mardal, K.A.; Ringstad, G. Sleep deprivation impairs molecular clearance from the human brain. Brain 2021, 144, 863-874. [CrossRef] [PubMed]

104. Irwin, M.; McClintick, J.; Costlow, C.; Fortner, M.; White, J.; Gillin, J.C. Partial night sleep deprivation reduces natural killer and celhdar immune responses in humans. FASEB J. 1996, 10, 643-653. [CrossRef] [PubMed]

105. Ibarra-Coronado, E.G.; Pérez-Torres, A.; Pantaleón-Martínez, A.M.; Velazquéz-Moctezuma, J.; Rodriguez-Mata, V.; MoralesMontor, J. Innate immunity modulation in the duodenal mucosa induced by REM sleep deprivation during infection with Trichinella spirallis. Sci. Rep. 2017, 7, 1-14.

106. Almondes, K.M.d.; Agudelo, H.A.M.; Correa, U.J. Impact of Sleep Deprivation on Emotional Regulation and the Immune System of Healthcare Workers as a Risk Factor for COVID 19: Practical Recommendations From a Task Force of the Latin American Association of Sleep Psychology. Front. Psychol. 2021, 12, 1625. [CrossRef] [PubMed]

107. Hancock, P.; Larner, A. Diagnostic utility of the Pittsburgh Sleep Quality Index in memory clinics. Int. J. Geriatr. Psychiatry 2009, 24, 1237-1241. [CrossRef] [PubMed]

108. Potvin, O.; Lorrain, D.; Forget, H.; Dubé, M.; Grenier, S.; Préville, M.; Hudon, C. Sleep quality and 1-year incident cognitive impairment in community-dwelling older adults. Sleep 2012, 35, 491-499. [CrossRef] [PubMed]

109. Shin, H.Y.; Han, H.J.; Shin, D.J.; Park, H.M.; Lee, Y.B.; Park, K.H. Sleep problems associated with behavioral and psychological symptoms as well as cognitive functions in Alzheimer's disease. J. Clin. Neurol. 2014, 10, 203-209. [CrossRef] [PubMed]

110. Mousavi, S.V.; Montazar, E.; Rezaei, S.; Hosseini, S.P. Sleep Quality and Cognitive Function in the Elderly Population. J. Sleep Sci. 2020, 5, 20-27. [CrossRef]

111. Kulkarni, P.M.; Xiao, Z.; Robinson, E.J.; Jami, A.S.; Zhang, J.; Zhou, H.; Henin, S.E.; Liu, A.A.; Osorio, R.S.; Wang, J.; et al. A deep learning approach for real-time detection of sleep spindles. J. Neural Eng. 2019, 16, 036004. [CrossRef]

112. Mikutta, C.; Feige, B.; Maier, J.G.; Hertenstein, E.; Holz, J.; Riemann, D.; Nissen, C. Phase-amplitude coupling of sleep slow oscillatory and spindle activity correlates with overnight memory consolidation. J. Sleep Res. 2019, 28, e12835. [CrossRef] [PubMed]

113. Astill, R.G.; Piantoni, G.; Raymann, R.J.; Vis, J.C.; Coppens, J.E.; Walker, M.P.; Stickgold, R.; Van Der Werf, Y.D.; Van Someren, E.J Sleep spindle and slow wave frequency reflect motor skill performance in primary school-age children. Front. Hum. Neurosci. 2014, 8, 910. [CrossRef] [PubMed]

114. Peters, K.R.; Ray, L.; Smith, V.; Smith, C. Changes in the density of stage 2 sleep spindles following motor learning in young and older adults. J. Sleep Res. 2008, 17, 23-33. [CrossRef]

115. Ventouras, E.M.; Ktonas, P.Y.; Tsekou, H.; Paparrigopoulos, T.; Kalatzis, I.; Soldatos, C.R. Independent component analysis for source localization of EEG sleep spindle components. Comput. Intell. Neurosci. 2010, 2010.. [CrossRef] 
116. Ventouras, E.M.; Ktonas, P.Y.; Tsekou, H.; Paparrigopoulos, T.; Kalatzis, I.; Soldatos, C.R. Slow and fast EEG sleep spindle component extraction using Independent Component Analysis. In Proceedings of the 2008 8th IEEE International Conference on BioInformatics and BioEngineering, Athens, Greece, 8-10 October 2008; pp. 1-6.

117. Ventouras, E.M.; Alevizos, I.; Ktonas, P.Y.; Tsekou, H.; Paparrigopoulos, T.; Kalatzis, I.; Soldatos, C.R.; Nikiforidis, G. Independent components of sleep spindles. In Proceedings of the 2007 29th Annual International Conference of the IEEE Engineering in Medicine and Biology Society, Lyon, France, 22-26 August 2007; pp. 4002-4005.

118. Backman, H.; Laajasalo, T.; Saukkonen, S.; Salmi, V.; Kivivuori, J.; Aronen, E.T. Are qualitative and quantitative sleep problems associated with delinquency when controlling for psychopathic features and parental supervision? J. Sleep Res. 2015, $24,543-548$. [CrossRef] [PubMed]

119. Åkerstedt, T.; Hume, K.; Minors, D.; Waterhouse, J. The subjective meaning of good sleep, an intraindividual approach using the Karolinska Sleep Diary. Percept. Mot. Skills 1994, 79, 287-296. [CrossRef] [PubMed]

120. Frauscher, B.; Ehrmann, L.; Högl, B. Defining muscle activities for assessment of rapid eye movement sleep behavior disorder: From a qualitative to a quantitative diagnostic level. Sleep Med. 2013, 14, 729-733. [CrossRef] [PubMed]

121. Choilek, S.; Karashima, A.; Motoike, I.; Katayama, N.; Kinoshita, K.; Nakao, M. Subjective sleep quality, quantitative sleep features, and their associations dependent on demographic characteristics, habitual sleep-wake patterns, and distinction of weekdays/weekends. Sleep Biol. Rhythm. 2021, 19, 1-13. [CrossRef]

122. Gupta, R.; Dahiya, S.; Bhatia, M.S. Effect of depression on sleep: Qualitative or quantitative? Indian J. Psychiatry 2009, 51, 117. [CrossRef] [PubMed] 